\title{
Stable muscle atrophy in long-term paraplegics with complete upper motor neuron lesion from 3- to 20-year SCI
}

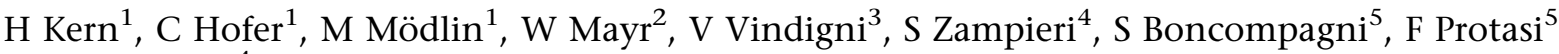 \\ and U Carraro ${ }^{4}$ \\ ${ }^{1}$ Department of Physical Medicine, Ludwig Boltzmann Institute of Electrostimulation and Physical Rehabilitation, \\ Wilhelminenspital, Vienna, Austria; ${ }^{2}$ Center of Biomedical Engineering and Physics, Medical University of Vienna, Vienna, Austria; \\ ${ }^{3}$ Unit of Plastic and Reconstructive Surgery, Department of Surgical and Medical Specialties, University of Padova, Padova, Italy; \\ ${ }^{4}$ Italian CNR Institute of Neuroscience, and Laboratory of Translational Myology, Interdepartmental Research Center of Myology \\ (cirMYO), Department of Biomedical Sciences, University of Padova, Padova, Italy and ${ }^{5}$ IIM-Inter-university Institute of Myology, \\ CeSI-Center for Research on Aging, University Gabriele d'Annunzio, Chieti, Italy
}

\begin{abstract}
Study design: Unrandomized trial.
Objectives: To investigate the structural and functional relationships and the progression of muscle atrophy up to 20 years of spastic paraplegia.

Setting: Clinical follow-up in Vienna, Austria; muscle biopsies analyzed by light microscopy in Padova and by electron microscopy (EM) in Chieti, Italy.

Methods: Force was measured as knee extension torque; trophism by computer tomography scan; tissue composition and fiber morphology by histopathology and EM.

Results: In the long-term group of patients (17.0 2.6 years), force and size of thigh muscles were only slightly different from those of mid-term subjects ( $2.2 \pm 0.5$ years). Histology and ultrastructure confirm that the difference in average size of muscle fibers between long-term and mid-term paralyzed leg muscles is actually very small. In addition, muscle fibers maintain the striated appearance characteristic of normal skeletal fibers even after 14-20 years of paralysis. Ultrastructural alterations of the activating and metabolic machineries, and the presence of fibers with lower motor neuron denervation features, may explain the low-force output and the reduced endurance of paretic muscles. Conclusion: The stable muscle atrophy that characterizes long-lasting spastic paraplegia suggests that there are no upper-time limits to begin a training program based on functional electrical stimulation. Spinal Cord (2008) 46, 293-304; doi:10.1038/sj.sc.3102131; published online 23 October 2007
\end{abstract}

Keywords: human muscle; paraplegia; upper motor neuron lesion; CT scan; biopsy; histopathology and electron microscopy

\section{Introduction}

Over the years, the use of functional electrical stimulation (FES) to restore movement of the limbs of paralyzed patients has been extensively discussed. ${ }^{1-3}$ There are numerous longterm spinal cord injury (SCI) patients (from 10 to 20 years after SCI) who could benefit from FES treatments, but information on their muscle conditions is scarce, in particular, on excitation-contraction (EC) coupling and myofibrillar apparatuses at the electron microscopy (EM) level.

We have recently studied long-term atrophy progression in patients suffering from complete lesion of lower motor neuron (Cauda Equina Syndrome). Our observations showed

Correspondence: Professor U Carraro, Department of Biomedical Sciences, University of Padova, Viale G Colombo 3, Padova, PD I-35121, Italy. E-mail: ugo.carraro@unipd.it

Received 2 February 2007; revised 31 August 2007; accepted 2 September 2007; published online 23 October 2007 that: (i) human skeletal muscles survive longer (in years) than generally accepted on the basis of experiments in rodents; ${ }^{4-6}$ (ii) recovery to clinically significant muscle size and function occurs in mid-term (3-5 years) lower motor neuron SCI subjects; ${ }^{7,8}$ but (iii) starting FES within the first year post-lesion results in a better recovery of muscle function than when started many years after SCI. ${ }^{9}$

To date, however, there is little knowledge about the longterm progression of muscle atrophy in upper motor neuron lesion (UML) patients . Indeed, the many reports published in the past have mostly studied muscle properties up to 3-5 years post-SCI. After the first few months, in which muscle mass decreases significantly, ${ }^{10-12}$ muscle atrophy reaches a steady state. Within the first month, the thickness of the muscle bulk, measured by ultrasound, decreases up to $40 \%{ }^{12,13}$ It is reasonable to indicate the period up to 3 months as the 'early phase' of disuse paraplegia. Afterwards, 
a 50\% stable atrophy in spastic incomplete paralysis is well documented up to 2 years after SCI. ${ }^{13-18}$ This time span (from 1.6 to 3.0 years) in the present paper is referred to as the 'mid-term' phase (MT). Information on the following periods, in particular, up to 20 years post-SCI (as in our 'longterm' group, LT), is quite poor. ${ }^{19}$

For this reason, we decided to compare, by functional and structural analyses, the muscles of SCI patients affected by long-term complete UML.

Here, we report that mid- (2 years after SCI) and long-term (15-20 years after injury) upper motoneuron-injured muscle does not undergo the degenerative process (muscle fiber substitution with adipose and fibrotic tissue) that devastates the muscles of 3-year lower motor neurons lesion subjects. ${ }^{7,8}$ In UML (spastic) paraplegia, human muscles seem to soon reach and sustain a stable atrophy.

On the other hand, they may contain variable amounts of lower motoneuron-denervated muscle fibers. Furthermore, our present EM observations on the structural alterations of the metabolic and activating apparatuses, could definitely account for the poor function of paraplegic muscles, which are weak and fatigable in spite of their not-so-small mass.

\section{Materials and methods}

\section{Patients}

The study included 10 subjects who had experienced traumatic SCI affecting the upper motor neuron (from T4 to T12). All subjects enrolled in the project were volunteers, who had received detailed information and had signed an informed consent. Biopsies were obtained as pre-FES sampling from patients who were going to undergo a 2-year FES treatment. Patients were divided into two groups: a mid-term group composed of six patients paralyzed for $2.2 \pm 0.5$ years and a long-term group formed by four patients paralyzed for $17.0 \pm 2.6$ years (mean \pm s.d.). All subjects were classified as ASIA A. Age, sex, body weight, height, etiology and level of SCI are reported in Table 1 . None of them were treated with FES during the last 2 years before muscle biopsy.

\section{Experimental setting}

Clinical and functional assessments, as well as follow-up and muscle biopsies, were performed at the Wilhelminenspital, Vienna, Austria. Light microscopy analyses were performed at the University of Padova, Italy, while EM observations were carried out at the University of Chieti, Italy.

\section{Computer tomography scan}

Complete cross-sectional area and density (measured in Hounsfield units, HU) of the quadriceps muscle and hamstrings were determined as described by Modlin et al. ${ }^{9}$ Patients were positioned so that the top of the trochanter major of both femur bones were aligned in the same plane of the computer tomography (CT) scan. This served as reference plane for the CT scan $20 \mathrm{~cm}$ below the trochanter major, which was used to determine the cross-sectional area and density of the muscle. The cross-sectional area is measured by manually marking the muscles (Figure 1) and calculating the area and the mean density (CT number or HU) of the selected area.

Table 1 Demographic data of the mid-term and long-term paraplegic subjects

\begin{tabular}{|c|c|c|c|c|c|c|c|c|}
\hline \multicolumn{9}{|c|}{ Patient status } \\
\hline & $\begin{array}{c}\text { Time of paralysis } \\
\text { to biopsy } \\
\text { years }\end{array}$ & $\begin{array}{l}\text { Age } \\
\text { years }\end{array}$ & Sex & $\begin{array}{l}\text { height } \\
\mathrm{cm}\end{array}$ & $\begin{array}{l}\text { weight } \\
\text { kg }\end{array}$ & level of lession & $\begin{array}{c}\text { Ashworth } \\
\text { kneejoint } \\
r / l\end{array}$ & Cause of paraplegia \\
\hline \multicolumn{9}{|c|}{ Mid term group: } \\
\hline MT1 & 1.6 & 29 & $\mathrm{~F}$ & 168 & 52 & Th 12 & $0 / 0$ & Fall from $3 \mathrm{~m}$ height \\
\hline MT2 & 1.8 & 20 & M & 185 & 92 & Th $7-8$ & $2 / 3$ & Motorcycle accident \\
\hline MT3 & 2.0 & 48 & M & 181 & 86 & Th 6-7 & $0 / 0$ & Bobsleigh accident \\
\hline MT4 & 2.3 & 30 & M & 175 & 65 & Th 4-5 & $0 / 0$ & Car accident \\
\hline MT5 & 2.4 & 28 & M & 170 & 80 & Th 4-5 & $1 / 1$ & Motorcycle accident \\
\hline MT6 & 3.0 & 34 & M & 174 & 70 & Th 5-7 & $0 / 0$ & Working accident \\
\hline mean & 2.2 & 31.5 & & 175.5 & 74.2 & & & \\
\hline s.d. & 0.5 & 9.3 & & 6.5 & 14.7 & & & \\
\hline \multicolumn{9}{|c|}{ Long term group: } \\
\hline LT1 & 14.0 & 32 & M & 180 & 78 & Th 8-9 & $0 / 0$ & Car accident \\
\hline LT2 & 16.8 & 37 & M & 190 & 72 & Th $11-12$ & $0 / 0$ & Motorcycle accident \\
\hline LT3 & 17.0 & 39 & M & 180 & 62 & Th 4-5 & $0 / 0$ & Motorcycle accident \\
\hline LT4 & 20.3 & 40 & M & 178 & 70 & Th 5-6 & $0 / 0$ & Motorcycle accident \\
\hline mean & 17.0 & 37.0 & & 182.0 & 70.5 & & & \\
\hline s.d. & 2.6 & 3.6 & & 5.4 & 6.6 & & & \\
\hline $\begin{array}{l}U \text {-Test } \\
(P \geqslant 0.05)\end{array}$ & $\begin{array}{c}U=0 \\
\text { Significant }\end{array}$ & $\begin{array}{c}U=5>2 \text { Not } \\
\text { significant }\end{array}$ & & $\begin{array}{c}U=5>2 \text { Not } \\
\text { significant }\end{array}$ & $\begin{array}{c}U=9>2 \text { Not } \\
\text { significant }\end{array}$ & & & \\
\hline
\end{tabular}

Abbreviations: LT, long term; MT, mid term.

All subjects had experienced traumatic spinal cord injury with complete paralysis of the lower limbs. Except for the time elapsed from injury to biopsy, there were no significant differences in age, height and weight between the MT (six subjects) and LT (four subjects) paralyzed groups. 

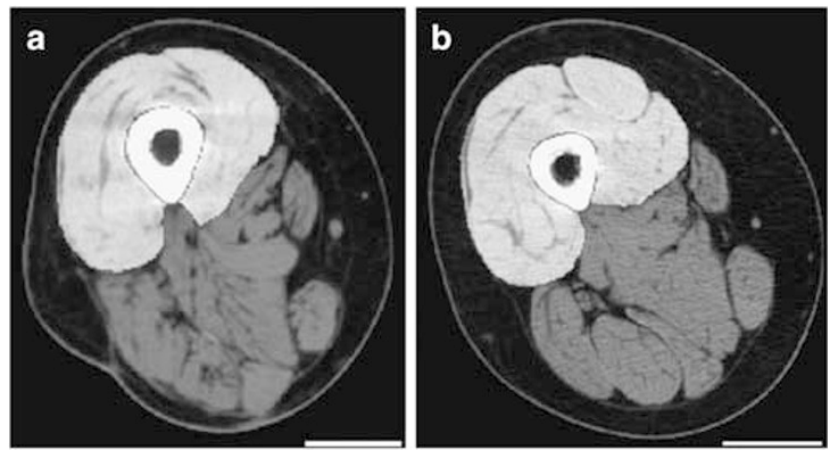

Figure 1 CT scans of the right thighs $20 \mathrm{~cm}$ below trochanter major. (a) Mid-term paralyzed: 2 years; (b) long-term paralyzed: 20 years. The appearance at the CT scan of tight muscles was not noticeably different between the two groups. The results reported in Table 1 confirmed that there were no significant differences in the average muscle size as time of paralysis increased. The quadriceps muscle is highlighted in the scans. Scale bars: $5 \mathrm{~cm}$. CT

Force measurement by knee extension torque

Measurement of force (induced by electrical stimulation) was performed by activating the quadriceps muscle by electrical stimulation, using a specifically designed chair. ${ }^{9}$ Force transducers, connected as a bridge circuit, were placed on a lever near the center of rotation. The isometric knee extension torque was measured at $90^{\circ}$ knee flexion by activating the quadriceps muscle with a standardized stimulation program. Force measurements were performed by activating thigh muscles with the large electrodes used for home training. This was both for the safety and to measure the actual force produced by the thigh muscles during training and functional sessions. ${ }^{20}$

\section{Analyses of muscle biopsies}

Through a small skin incision (6 $\mathrm{mm}$ in diameter), needle muscle biopsies were taken from the right and left vastus lateralis muscles at a single time point for each patient, as described by Kern et al. ${ }^{7}$ The resulting specimens were then prepared either for light and/or EM.

Hematoxylin and eosin. Cryosections ( $10 \mu \mathrm{m}$ thick) of frozen biopsies were stained with hematoxylin and eosin (H\&E), using conventional techniques. Morphometric analyses were performed as described by Rossini et al. ${ }^{21}$ Briefly, three 10$\mu \mathrm{m}$-thick sections were collected on glass slides and stained with $H \& E$ using conventional techniques. Images were acquired using a Zeiss microscope connected to a Leica DC $300 F$ camera at low magnification, under the same conditions that were used to photograph a reference ruler. The minimum transverse diameter of each muscle fiber was measured against the reference ruler. The muscle fibers were grouped and the relative percentile was plotted in $5 \mu \mathrm{m}$ steps. Morphometric analysis was performed with Scion Image for Windows version Beta 4.0.2 (2000 Scion Corporation, Frederick, MD, USA), free software downloaded from the web site: www.scioncorp.com. Tissue type distribution (relative content of interstitial tissue and cumulative muscle fiber areas) was determined using the Adobe Photoshop software (Adobe Systems Incorporated, San Jose, CA, USA).

Immunohistochemistry. Cryosections were labeled with antibodies anti-NCAM (neural cell adhesion molecule) (from Chemicon International, Milan, Italy), as described by Rossini et al. ${ }^{22}$

Preparation of muscle specimens for transmission electron microscopy. Bioptic samples were fixed and stained as described by Kern et al. ${ }^{7}$ Briefly, samples were fixed for $2 \mathrm{~h}$ in icecold $2.5 \%$ glutaraldehyde in $0.2 \mathrm{M}$ sodium cacodylate buffer, $\mathrm{pH} 7.2$, followed by a buffer rinse and $1 \mathrm{~h}$ fixation in $1 \%$ osmium tetraoxide. Specimens were then dehydrated in a graded series of ethanol solutions and embedded in epoxy resin. Ultrathin sections (approximately $40 \mathrm{~nm}$ ) were cut in Leica Ultracut R (Leica Microsystem, Vienna, Austria) using a Diatome diamond knife (DiatomeLtd., CH-2501 Biel, Switzerlad) and stained in 4\% uranyl acetate and lead citrate. Stained sections were then examined with a FP 505 Morgagni Series 268D electron microscope (FEI Company, Brno, Czech Republic), equipped with Megaview III digital camera and Soft Imaging System (Münster, Germany). Figures were mounted and labeled using Adobe Photoshop v7.0.

\section{Statistical analysis}

The number of long-term paraplegic patients was small, due to the scarcity of subjects willing to undergo muscle biopsy. As the small sample size did not grant normal value distribution, the Mann-Whitney $U$-test was used to establish the statistical significance of the observed changes. Larger samplings of the morphometric data allowed the use of Student's $t$-test.

\section{Statement of ethics}

We certify that all applicable regulations concerning the ethical use of human volunteers were followed during the course of this research. (Approval: EK-03-035-0403).

\section{Results}

\section{CT scan}

Figure 1 shows two representative examples of the thigh cross-sectional area of mid- and long-term paraplegics. Crosssectional area and quality of the muscle tissue are very similar in the left and right legs of all patients (Table 2). In the mid-term group, the average cross-sectional area of the quadriceps muscle is $49.84 \pm 12.76 \mathrm{~cm}^{2}$, (with a mean tissue density of $41.37 \pm 4.39 \mathrm{HU}$ ), whereas in long-term paraplegics is $38.97 \pm 5.09 \mathrm{~cm}^{2}$ (mean tissue density of $38.89 \pm$ $2.37 \mathrm{HU})$. The statistical analysis indicated that the differences were not significant, even if both values appear to be smaller in the second group of patients.

\section{Force measurement}

Table 2 shows the results obtained measuring the knee torque of patients during electrical stimulation: mid-term paraplegics have an average knee torque of $26.33 \pm$ $15.21 \mathrm{Nm}$, while in the long-term group the average torque 
is $16.64 \pm 7.8 \mathrm{Nm}$. The high standard deviations reflect the fact that measurement of muscle strength is biased by the undesired activation of the antagonistic muscles (see Discussion).

Histological analysis

Figure $2 \mathrm{a}$ shows an H\&E stain of a transverse section of a normal human muscle biopsy, characterized by well-packed fibers (presenting slightly different sizes and shapes) and minimal interstitial tissue. Figures $2 \mathrm{~b}-\mathrm{f}$ show mid-term (B,
1.6 years; C, 1.8 years; D, 2.0 years; E, 2.5 years; F, 3.0 years), while Figures $2 \mathrm{~g}-\mathrm{h}$ display long-term (G, 14.0 years; $\mathrm{H}, 16.8$ years, I, 17.0 years, J, 20.3 years) UML biopsies. The muscle fibers show size variability, the large majority being atrophic (mid-term group mean fiber diameter $31.39 \pm 21.19 \mu \mathrm{m}$ and long-term group $36.09 \pm 18.35 \mu \mathrm{m}$ ). Muscle fibers larger than normal are marked by the asterisks. On the other hand, very small fibers, presenting the features of severe atrophy (being similar to those of patients with complete lower motor neuron lesion $^{7}$ ) are indicated by arrows. Interstitial space between muscle fibers is enlarged in comparison to normal

Table 2 CT Scan and knee extension torque of quadriceps muscle in mid-term and long-term paraplegic patients

\begin{tabular}{|c|c|c|c|c|c|c|c|c|c|c|c|}
\hline & & \multicolumn{4}{|c|}{ Quadriceps $20 \mathrm{~cm}$} & \multicolumn{4}{|c|}{ Hamstrings $20 \mathrm{~cm}$} & \multirow{2}{*}{\multicolumn{2}{|c|}{$\begin{array}{c}\text { Force at } 120 \mathrm{Vss} \\
\mathrm{Nm}\end{array}$}} \\
\hline & & & $\begin{array}{c}\text { Density } \\
\text { HU }\end{array}$ & & $\begin{array}{l}\text { Area } \\
\mathrm{cm}^{2}\end{array}$ & & $\begin{array}{c}\text { Density } \\
\text { HU }\end{array}$ & & $\begin{array}{l}\text { Area } \\
\mathrm{cm}^{2}\end{array}$ & & \\
\hline \multicolumn{12}{|c|}{ Short term group: } \\
\hline \multirow[t]{2}{*}{ ST1 } & left & & 36.00 & & 26.66 & & 29.00 & & 29.97 & & 7.70 \\
\hline & right & & 33.00 & & 26.50 & & 22.00 & & 25.96 & & 3.40 \\
\hline \multirow[t]{2}{*}{ ST2 } & left & & 40.00 & & 42.97 & & 32.00 & & 55.48 & & 20.70 \\
\hline & right & & 40.00 & & 41.82 & & 31.00 & & 50.93 & & 16.60 \\
\hline \multirow[t]{2}{*}{ ST3 } & left & & 43.81 & & 47.85 & & 28.24 & & 58.99 & & 19.20 \\
\hline & right & & 42.17 & & 47.52 & & 34.23 & & 59.16 & & 25.00 \\
\hline \multirow[t]{2}{*}{ ST4 } & left & & 50.00 & & 37.05 & & 38.00 & & 36.18 & & 17.10 \\
\hline & right & & 48.30 & & 36.96 & & 39.15 & & 36.28 & & 28.70 \\
\hline \multirow[t]{2}{*}{ ST5 } & left & & 43.55 & & 53.83 & & 35.17 & & 60.58 & & 37.50 \\
\hline & right & & 42.68 & & 49.16 & & 34.15 & & 57.04 & & 45.30 \\
\hline \multirow[t]{3}{*}{ ST6 } & left & & 42.82 & & 48.61 & & 39.21 & & 55.48 & & 51.30 \\
\hline & right & & 41.09 & & 53.03 & & 36.01 & & 58.44 & & 43.50 \\
\hline & & $\begin{array}{l}\text { Mean density } \\
\text { s.d. }\end{array}$ & $\begin{array}{r}41.95 \\
4.64\end{array}$ & $\begin{array}{l}\text { Mean area } \\
\text { s.d. }\end{array}$ & $\begin{array}{r}42.66 \\
9.26\end{array}$ & $\begin{array}{l}\text { Mean density } \\
\text { s.d. }\end{array}$ & $\begin{array}{r}33.18 \\
5.07\end{array}$ & $\begin{array}{c}\text { Mean area } \\
\text { s.d. }\end{array}$ & $\begin{array}{l}48.71 \\
12.78\end{array}$ & $\begin{array}{l}\text { Mean force } \\
\text { s.d. }\end{array}$ & $\begin{array}{l}26.33 \\
15.21\end{array}$ \\
\hline \multicolumn{12}{|c|}{ Long term group: } \\
\hline \multirow[t]{2}{*}{ LT1 } & left & & 41.49 & & 38.12 & & 35.72 & & 44.24 & & 25.50 \\
\hline & right & & 41.84 & & 38.75 & & 37.50 & & 44.24 & & 21.50 \\
\hline \multirow[t]{2}{*}{ LT2 } & left & & a & & 36.96 & & a & & 40.87 & & 5.50 \\
\hline & right & & a & & 38.28 & & a & & 40.87 & & 3.70 \\
\hline \multirow[t]{2}{*}{ LT3 } & left & & 36.00 & & 29.79 & & 39.00 & & 33.87 & & 18.30 \\
\hline & right & & 37.00 & & 29.77 & & 42.00 & & 33.87 & & 20.00 \\
\hline \multirow[t]{3}{*}{ LT4 } & left & & 39.00 & & 36.61 & & 35.00 & & 43.22 & & 17.50 \\
\hline & right & & 38.00 & & 37.17 & & 30.00 & & 43.22 & & 21.10 \\
\hline & & $\begin{array}{c}\text { Mean density } \\
\text { s.d. }\end{array}$ & $\begin{array}{r}38.89 \\
2.37\end{array}$ & $\begin{array}{l}\text { Mean area } \\
\text { s.d. }\end{array}$ & $\begin{array}{r}35.68 \\
3.71\end{array}$ & $\begin{array}{c}\text { Mean density } \\
\text { s.d. }\end{array}$ & $\begin{array}{r}36.54 \\
4.06\end{array}$ & $\begin{array}{l}\text { Mean area } \\
\text { s.d. }\end{array}$ & $\begin{array}{r}40.55 \\
4.33\end{array}$ & $\begin{array}{l}\text { Mean force } \\
\text { s.d. }\end{array}$ & $\begin{array}{r}16.64 \\
7.82\end{array}$ \\
\hline $\begin{array}{l}U \text {-test } \\
(P \geqslant 0.05)\end{array}$ & & Density & $\begin{array}{c}U=16>14 \\
\text { Not } \\
\text { significant }\end{array}$ & $\begin{array}{l}\text { Area } \\
\text { QU }\end{array}$ & $\begin{array}{c}U=24>22 \\
\text { Not } \\
\text { significant }\end{array}$ & $\begin{array}{c}\text { density } \\
\text { HU }\end{array}$ & $\begin{array}{c}U=23>14 \\
\text { Not } \\
\text { significant }\end{array}$ & $\begin{array}{l}\text { Area } \\
\text { Ham }\end{array}$ & $\begin{array}{c}U=27>22 \\
\text { Not } \\
\text { significant }\end{array}$ & Force & $\begin{array}{c}U=34>22 \\
\text { (from table) } \\
\text { Not significant }\end{array}$ \\
\hline
\end{tabular}

Abbreviations: LT, long term; MT, mid term.

Cross-sectional area and quality of muscles were very similar in left and right legs of of each patient. Furthermore, no significant differences were present between MT and LT groups (tested with Man-Whitney- $U$-Test). Force was assessed during stimulation-induced, isometric knee extension. While the inter-leg values were in reasonable agreement, the inter-subject variability was very high in both mid- and long-term groups (mid versus long $U$-Test $=34$, non significant).

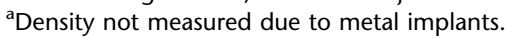

Figure 2 Morphological appearance of normal and paraplegic human muscle. H\&E stain: (a) normal adult human muscle; (b-f) mid-term (b, 1.6 year; c, 1.8 years; $\mathbf{d}, 2.0$ years; e, 2.5 years; $\mathbf{f}, 3.0$ years); and ( $\mathbf{g}$ and $\mathbf{h}$ ) long-term ( $\mathbf{g}, 14.0$ years, $\mathbf{h} ; 16.8$ years; $\mathbf{i}, 17.0$ years; $\mathbf{j}, 20.3$ years) upper motor neuron lesion paraplegics. Myofiber profiles in normal muscle were separated by minimal interstitial tissue, appearing closely packed. In both mid-term (6 subjects, 12 biopsies) and long-term (4 subjects, 8 biopsies) groups the interstitial space between fibers was slightly enlarged. Fiber size was also more variable than in normal muscle, with some fibers appearing unusually large (asterisks) and a small percentage of them presenting extremely small diameters (arrows). The results reported in Table 3 (including the female participant in midterm group) and Table 4 (including/excluding the female participant in mid-term group) confirmed that there were no significant differences in the average muscle size as time of paralysis increased. Scale bars: $100 \mu \mathrm{m}$. 
muscle: in fact, morphometry indicates that the interstitial tissue, which in normal muscle is only $4 \%$ (Figure 3a), covers 30 and 28\%, respectively, in mid- (Figure 3c) and long-term
(Figure 3e) paralyzed subjects ( $t$-test: $P<0.001)$. The slight difference between the two SCI groups (30 vs $28 \%$ ) was not statistically significant.
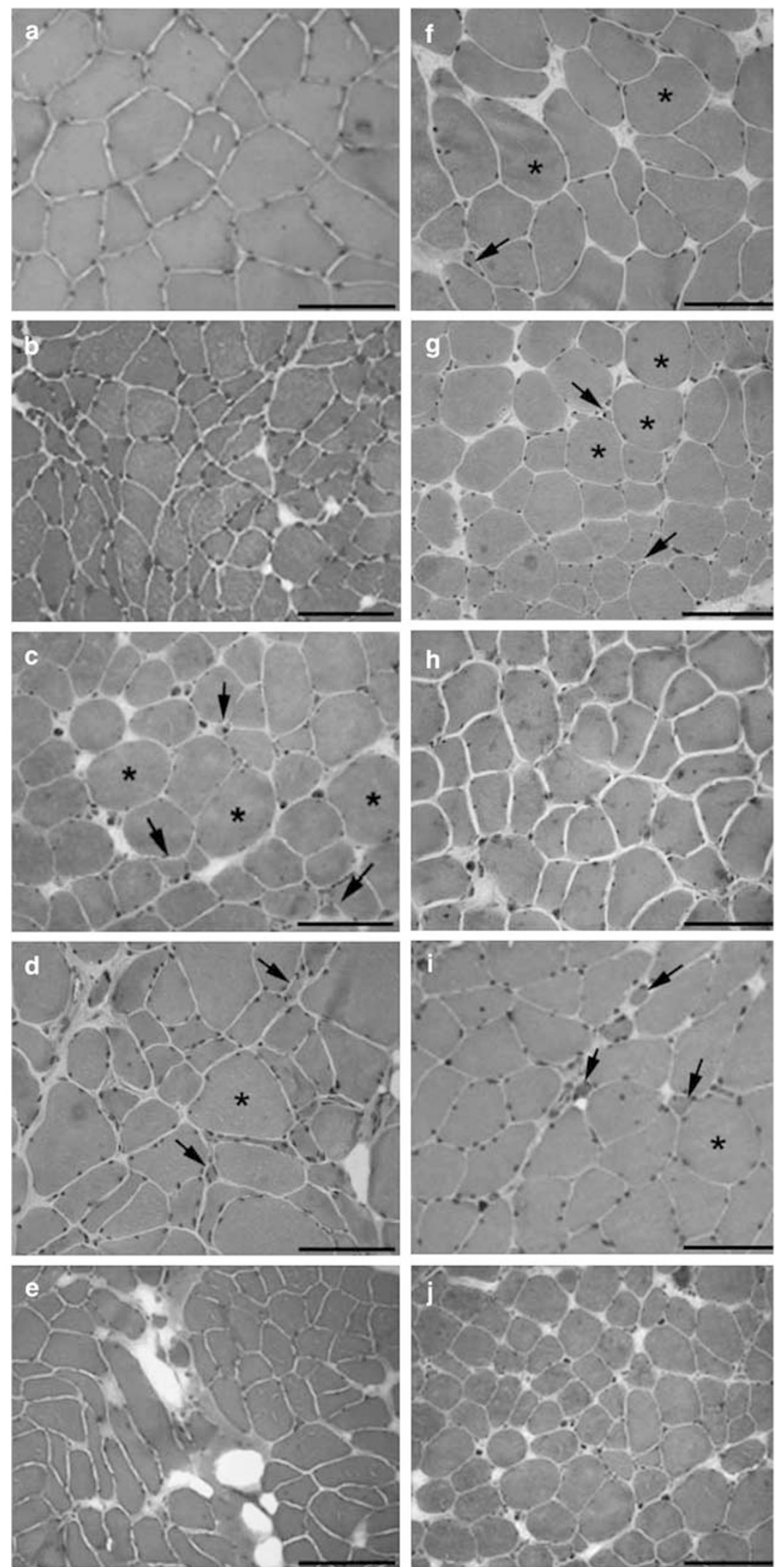
Table 3 shows that the mean size of muscle fibers is very similar in the left and right legs of each patients. However, the analysis of the fiber size distribution (Figure 3) of normal (panel b), mid-term (panel d) and long-term (panel f) paretic

a

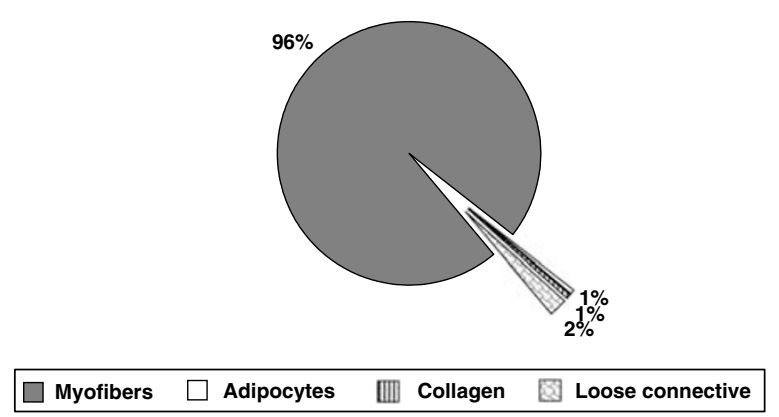

C

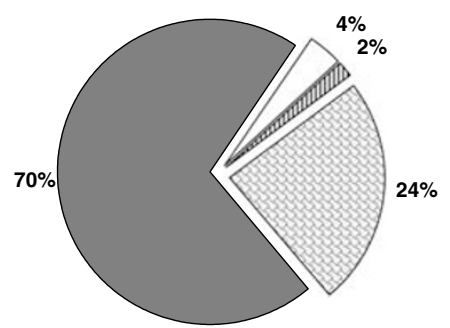

$\square$ Myofibers $\square$ Adipocytes $\quad \square$ Collagen $\quad$ Loose connective

e

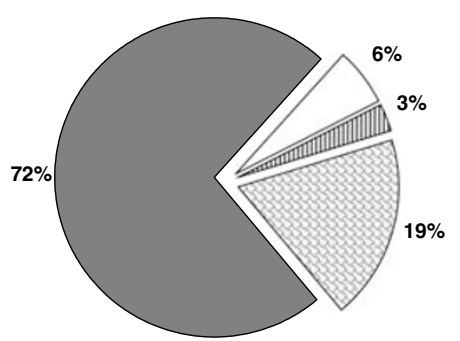

$\square$ Myofibers $\square$ Adipocytes $\square$ Collagen $\quad$ Loose connective

g

Upper motoneuron lesion - Myofiber size correlation

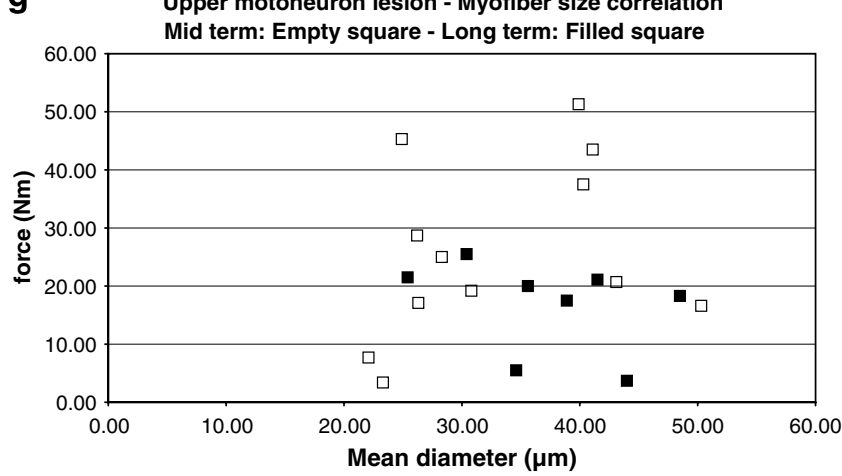

muscles indicates that at least two different muscle fiber populations are present in the long-term group (Figure 3f): severely atrophic fibers (diameter: $10 \mu \mathrm{m}$ ) and atrophic fibers (diameter: $40 \mu \mathrm{m}$ ). In the mid-term sample (Figure $3 \mathrm{~d}$ ) $23.2 \%$
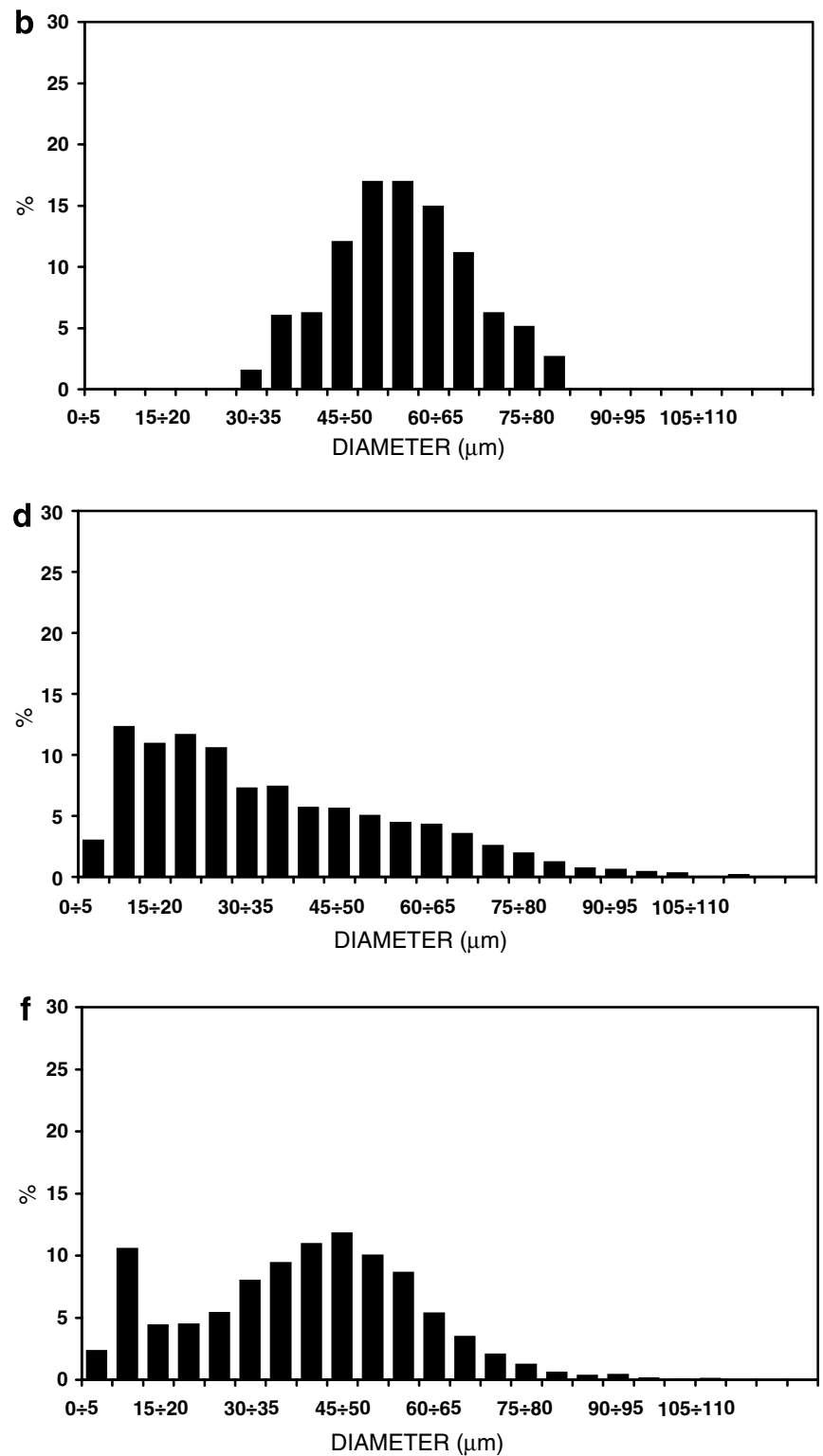

$\mathbf{h}$

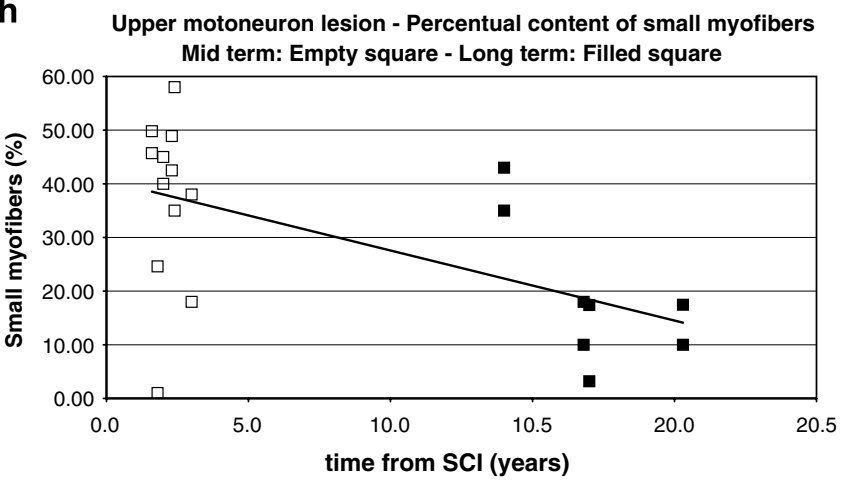


of fibers have a diameter smaller than $15 \mu \mathrm{m}$, whereas in the long-term group (Figure 3f) this percentage was slightly smaller, $17.0 \%$ (non significant; $t$-test, $P=0.09$ ).

Very small fibers are likely those that lost contact with the lower motor neuron. This interpretation is based on their

Table 3 Minimum transverse diameter of myofibers in vastus lateralis muscle in mid-term and long-term spastic patients

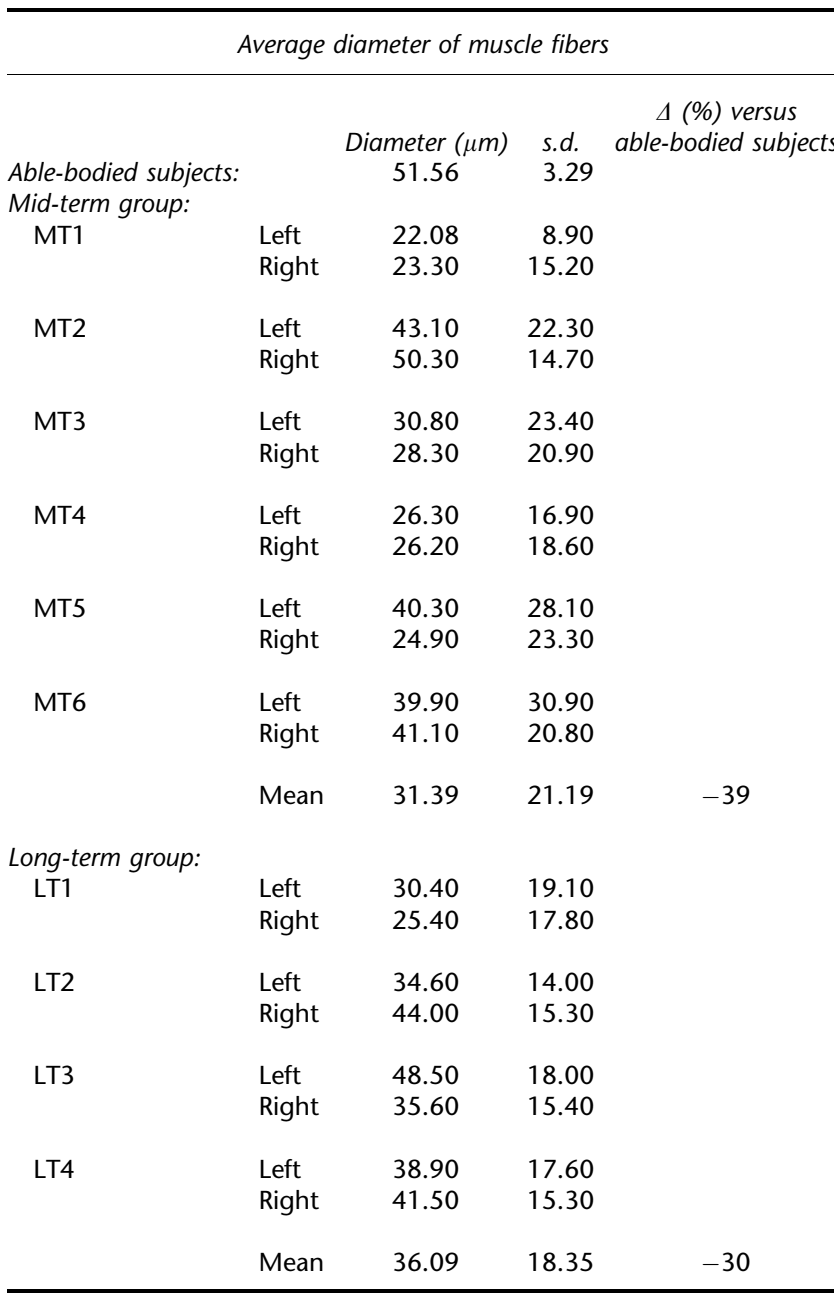

Abbreviations: $\mathrm{LT}$, long term; MT, mid term.

Size of myofibers (at least 200 muscle fibers were measured in each biopsy) was very similar in left and right legs of all mid-term (6 subjects, 12 biopsies) and long-term (4 subjects, 8 biopsies) patients. The increase in diameter of the long-term group $[\Delta(\%)$ versus mid-term $=15]$ was not statistically significant (mid-versus long-term $U$-Test $=34$, non significant). labeling (red cells in Figure 4) with an antibody against NCAM (or N-CAM, also the cluster of differentiation CD56), a sound marker of muscle fiber peripheral denervation, ${ }^{22}$ as well as on their EM morphology (see following section for additional evidence). In both SCI groups, there is no relationship between time of SCI and percentage of muscle fibers displaying severe atrophy (Figure $3 \mathrm{~h}$ ), nor between force and average muscle fiber diameter of the quadriceps muscle (Figure 3g), suggesting that no substantial differences exist between the two groups of patients.

One of the patients studied (MT1, see Table 4), the only female participant, presents some characteristics that are different from those of others patients. She has the lowest thoracic level of SCI (T12) and, despite the fact that she had been injured for the shortest period at the time of muscle biopsy, her muscles are more compromised than that of the other patients (severely atrophic). Because of this, it is difficult to decide if this patient should be included in the study or not.

In Table 4, we compared long-term and mid-term groups either including or excluding this patient. By excluding the female participant MT1, the difference in average force between long-term and mid-term groups is larger than in the analysis that includes the patient MT1. This difference, though, is not significant. Also CT scan analysis and muscle

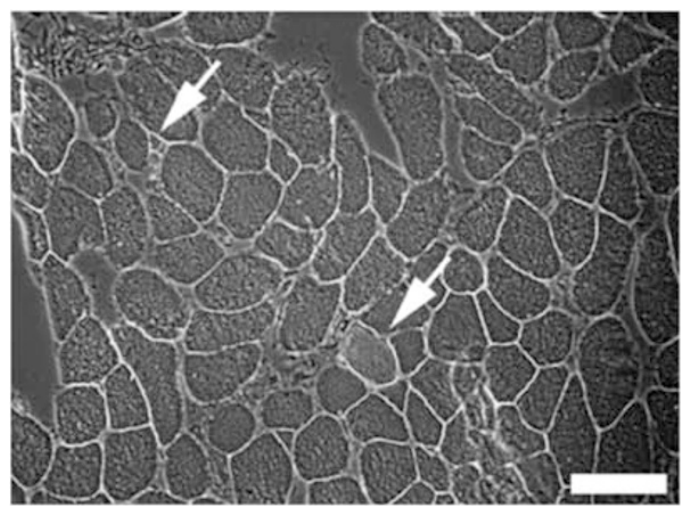

Figure 4 N-CAM staining of a muscle biopsy from the long-term paraplegic group. Denervated myofibers (red outlines) of different size and stain intensity were present in this 17-year upper motor neuron complete paraplegic muscle after anti-NCAM monoclonal labeling. Nuclei were counterstained with Hoechst 33258 (blue), while myofibers outlines were revealed by contrast phase microscopy. Scale bars: $100 \mu \mathrm{m}$. NCAM, neural cell adhesion molecule.

Figure 3 Tissue type morphometry, cumulative fiber size distribution and percent content of small myofibers in mid-term (MT) and long-term (LT) paraplegics. Tissue type morphometry: (a) normal human muscle; (c and e) MT and LT paraplegics. At least 200 muscle fibers were measured in each biopsy. The most significant difference between normal and paralyzed muscle was an increase in loose connective tissue with a comparable loss of muscle mass. On the other hand, no significant differences existed between MT- and LT-paralyzed muscles. The minimal differences between paraplegics were not significant $(P=0.31)$, but each of them differed significantly from normal muscle $(P<0.001)$. Cumulative fiber size distributions: (b) Normal adult muscle; (d and f) MT and LT paraplegics. The LT group clearly comprised two distinct populations of myofibers: severely atrophic (median diameter: $10 \mu \mathrm{m}$ ) and slightly atrophied (median diameter: $40 \mu \mathrm{m}$ ). On the other hand, in the MT group there was a larger percentage of fibers with an intermediate diameter ranging from 10 to $20 \mu \mathrm{m}$. (g) Shown here is that in both mid-term (six subjects) and long-term (four subjects) groups there was no correlation between force of quadriceps muscle and mean fiber diameter. (h) Here we show that in both mid-term and long-term groups there was no correlation between time after spinal cord injury and percent content of small myofibers. 
Table 4 Correlation between mid-term and long-term groups, either including or excluding the MT1 female subject

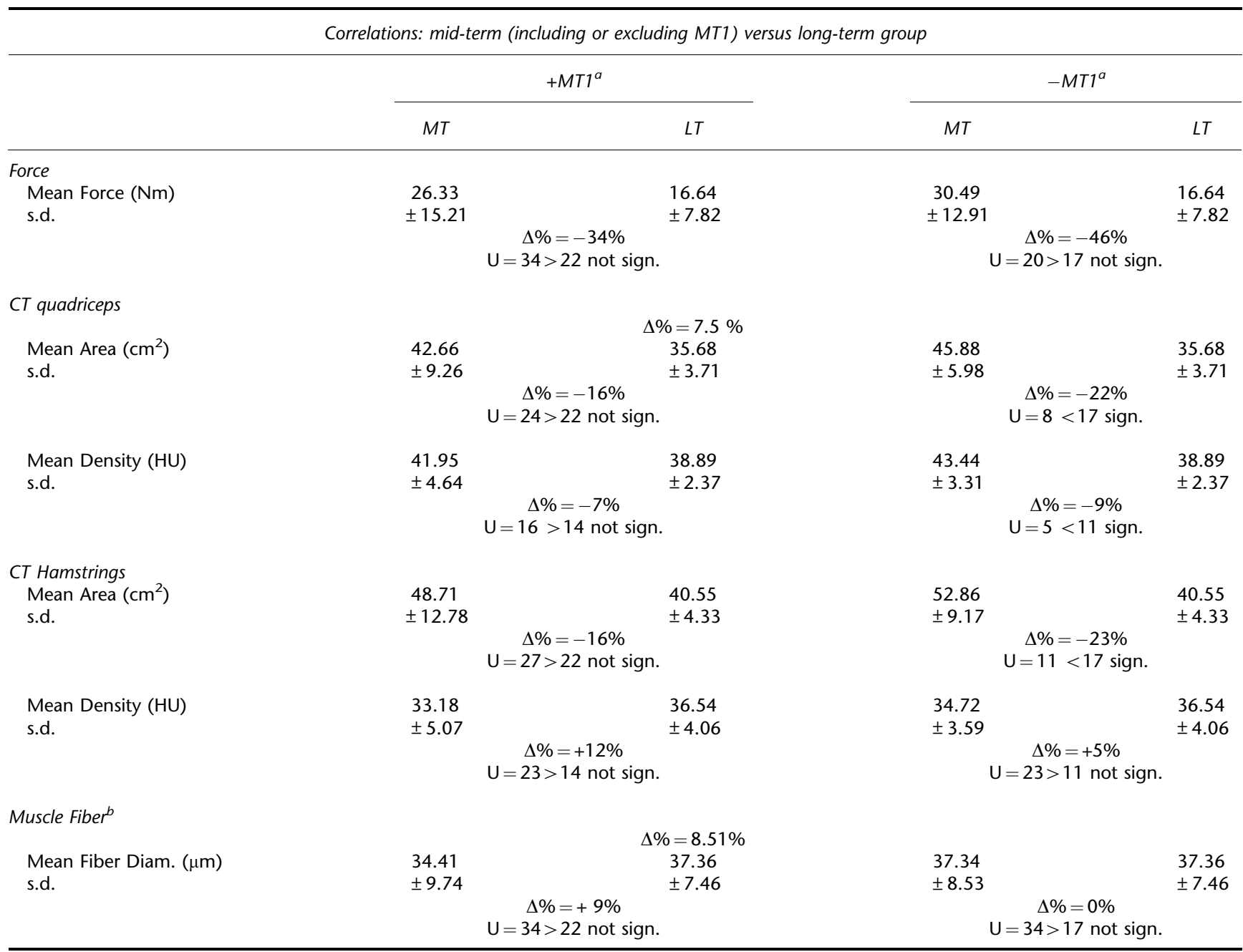

Abbreviations: LT, long term; MT, mid term.

We compared MT and LT groups either including or excluding this patient. By excluding the female participant MT1, the difference in average force between LT and MT groups is larger than in the analysis that includes the patient MT1. This difference, though, remains not significant. Also CT scan analysis and muscle morphometry shows a larger difference between the two groups when the MT1 sample is included in the analysis (up to 15-20\% at the most). Finally, the area of quadricep versus hamstring muscles in the MT group including MT1, in the MT group excluding MT1, and in the long-term group, are 87, 87, and 88\%, respectively.

morphometry shows a larger difference between the two groups when the MT1 sample is included in the analysis (up to $15-20 \%$ at the most), but seldom the differences are statistically significant. Finally, the area of quadricep vs hamstring muscles in the mid-term group including MT1 (6 subjects, 12 thighs), excluding MT1 (5 subjects, 10 thighs) and in the long-term group (4 subjects, 8 thighs) are 87,87 and $88 \%$, respectively, further suggesting that inclusion of the female participant did not significantly change the results.

\section{Ultrastructural analysis of biopsies from long-term spastic patients}

Figures $5 \mathrm{a}$ and $\mathrm{b}$ show the ultrastructure of a normal human muscle fiber. ${ }^{23-25}$ The contractile apparatus, formed by long cylinders called myofibrils, is formed by basic elements, the sarcomeres, which are delimited by $\mathrm{Z}$ lines (Figure 5a, black arrows). Sarcomeres of adjacent myofibrils are usually quite well aligned, forming the dark-pale cross striation that characterizes skeletal muscle. Mitochondria are mostly placed next to the $\mathrm{Z}$ lines (empty arrows) and next to EC coupling units (Figure 5b). ${ }^{26,27}$ EC coupling units, or triads, are formed by one transverse tubule, carrying the action potential and two apposed sarcoplasmic reticulum vesicles, containing the $\mathrm{Ca}^{2+}$ needed to activate muscle contraction (Figure $5 b) .^{24}$

Fiber ultrastructure of paraplegic patients (Figures 5c, d and 6) may not only explain why muscles of paraplegics still develop force, but also why their strength and endurance is decreased when compared to normal subjects. The first important observation is that muscle fibers from paraplegics are either quite large, presenting a fairly well-preserved contractile material, or severely atrophic. Muscle fibers were 

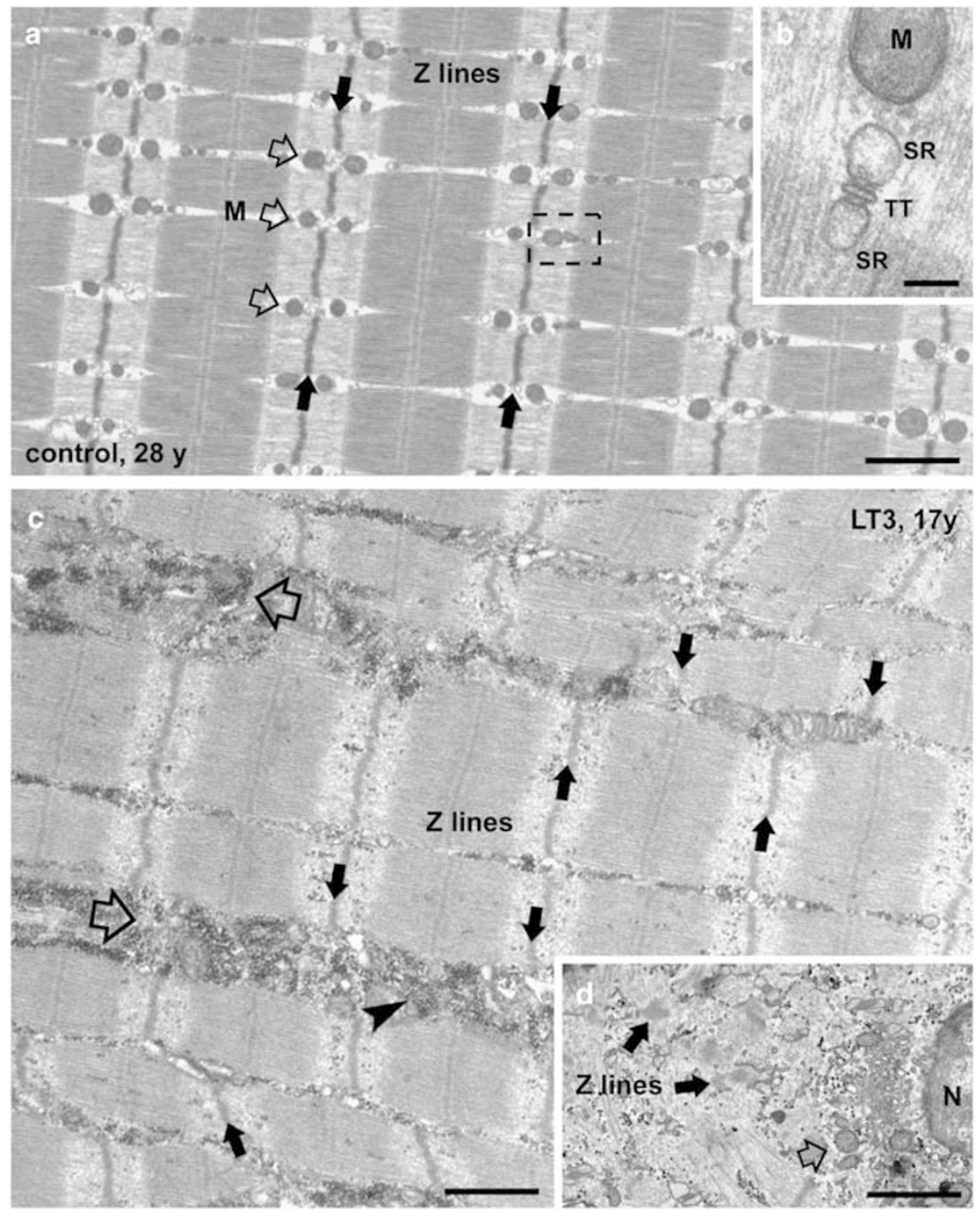

Figure 5 Electron micrographs of longitudinal sections from muscle fibers of control and long-term spastic patients. (a and b) Skeletal muscles from control subjects (vastus lateralis, 28 years of age, see (Boncompagni et al., 2006)) were characterized by a highly ordered internal organization. The contractile apparatus was formed by sarcomeres, delimited by Z lines (black arrows) and well aligned with those of adjacent myofibrils. Mitochondria (M) were mostly positioned next to the $Z$ lines (empty arrows) and next to excitation-contraction (EC) coupling units, or triads (b). (b) An area similar to that marked by the box in (a). (c and d) Muscle fibers from paralyzed patients were either quite large, with a fairly well-preserved contractile material (c), or severely atrophic and presenting classic features of denervation (d). In large fibers (c), the precise alignment of sarcomeres of adjacent myofibrils was partially lost (black arrows). Mitochondria also lost their specific positioning and were found mostly in clusters just below the sarcolemma (data not shown) or between myofibrils (empty arrows). In severely atrophic fibers (d), myofibrils were completely disassembled, Z lines were thickened (black arrows) and mitochondria were clustered (empty arrow). N, nucleus. Scale bars: $\mathbf{a}, \mathbf{c}$ and $\mathbf{d}, 1 \mu \mathrm{m} ; \mathbf{b}, 0.1 \mu \mathrm{m}$.

classified either as striated fiber, if clear cross-striation was visible in the all fiber interior (such as Figure $5 \mathrm{c}$ ), or as severely atrophic fibers in the presence of disorganization of the contractile apparatus, thickening of the $\mathrm{Z}$ line or degeneration (such as Figure $5 \mathrm{~d}$ ). Most of the fibers $(\geqslant 77 \%)$ were large and presented a myoplasm filled with contractile material organized in myofibrils and sarcomeres (Table 5, column B). A variable percentage of fibers were instead severely atrophic (4-23\%, Table 5, column C) and resemble those found in patients that lost their peripheral nerve endings. ${ }^{7}$

Some peculiar features allowed us to clearly distinguish large striated fibers in our patients from fibers of controls. ${ }^{25}$
The myofibrillar apparatus, while quite well preserved, is in general less ordered than in normal muscle (Figure 5c, black arrows). In addition, large and abnormal areas filled with glycogen granules, mitochondria and vesicles were also frequent (Figures 5c and 6a, empty arrows). Observation at higher magnification of those regions and of the intermyofibrillar spaces indicated that both metabolic and EC coupling apparatuses were significantly altered (Figure 6). Mitochondria usually lost their specific positioning next to $\mathrm{Z}$ lines and were found mostly in clusters just below the sarcolemma (not shown) or between myofibrils (Figure 5c, empty arrows). These areas, also filled with large accumulation of glycogen granules (Figures 5 and 6, arrowheads), contain sarcoplasmic 

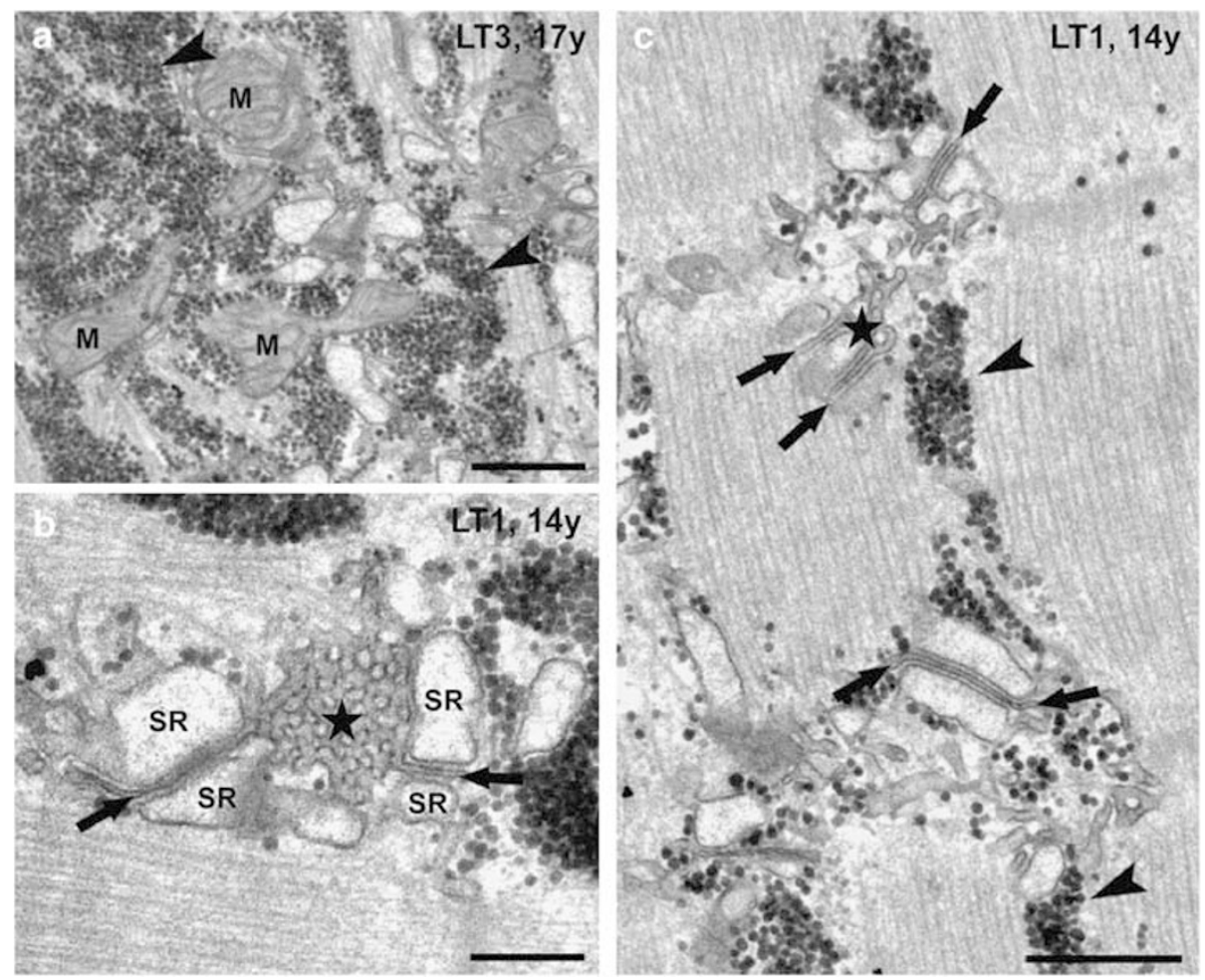

Figure 6 Electron micrograph details of mitochondria clusters and abnormal excitation-contraction coupling units. (a) Typical cluster of mitochondria (M) in an area filled with vesicles and glycogen granules (arrowheads). (b and c) Sarcoplasmic reticulum (SR) vesicles forming defective triads were unusually shaped, swollen and in contact with transverse tubules (black arrows), which in turn were misoriented and/or abnormally convoluted. The alteration/disruption of the sarcotubular system also involved the formation of honeycomb structures and of multiple junctions (black stars). The arrowhead in (c) indicates an accumulation of glycogen granules. Scale bars: $\mathbf{a}$ and $\mathbf{c}, 0.5 \mu \mathrm{m} ; \mathbf{b}, 0.25 \mu \mathrm{m}$.

Table 5 Electron microscopy characterization of long-term spastic patients

\begin{tabular}{lccccc}
\hline \multicolumn{4}{c}{ Electron Microscopy } \\
\hline Patients & Age at the time of biopsy (years) & Time between & & & \\
SCl and biopsy (years) & Analyzed fibers & Striated fibers & Severely atrophic fibers \\
\hline LT1 & 32 & 14.0 & 21 & $17(81 \%)$ & $4(19 \%)$ \\
LT2 & 37 & 16.8 & 24 & $23(96 \%)$ & $1(4 \%)$ \\
LT3 & 39 & 17.0 & 13 & $10(77 \%)$ & $3(23 \%)$ \\
LT4 & 40 & 20.3 & 19 & $15(79 \%)$ & $4(21 \%)$ \\
\hline
\end{tabular}

Abbreviations: LT, long term; MT, mid term.

In each patient, at least 13 fibers were closely analyzed at the electron-microscopy level (column A). The majority of fibers (77\% or more) presented a myoplasm filled with contractile material organized in myofibrils and sarcomeres (column B, see also Figure 5). Some fibers presenting classic features of denervation (i.e., disgregation of the myofibrillar structure) were also found in these patients (4-23\%, column C); these latter fibers resembled those found in patients who had lost their peripheral nerve endings. ${ }^{7}$

reticulum, which is often unusually fragmented (Figure 6a). The EC coupling apparatus, responsible for triggering muscle contraction by releasing $\mathrm{Ca}^{2+}$ in response to the action potentials, also presented abnormal features: unusually shaped and swollen sarcoplasmic reticulum vesicles formed defective triads (compare Figure $6 \mathrm{~b}$ with Figure $5 \mathrm{~b}$ ) and were in contact with transverse tubules that were often misoriented and/or abnormally convoluted (Figures $6 \mathrm{~b}$ and c, black arrows). The alteration/disruption of the sarcotubular system also involved the formation of honeycomb structures and multiple junctions (Figures $6 \mathrm{~b}$ and c, stars).

\section{Discussion}

Recent work published by our laboratories have focused on studying the long-term progression of muscle atrophy to muscle degeneration in patients affected by lower motor neurons lesion. ${ }^{7-9}$ However, up to now, not much was known about the long-term progression of muscle atrophy in UML patients, that is, subjects in which muscle of the lower extremities is still connected to motor neurons (spastic patients). An understanding of the specific changes that occur in muscle fibers and the extracellular matrix in long-term 
spastic patients may facilitate the development of new therapeutic strategies.

The most important finding of the present study is that in complete UML the progression of atrophy, after an early fast phase in which muscle mass decreases significantly, ${ }^{10-12}$ is extremely slow for many years (up to 20). In fact, after the first few months, muscle atrophy reaches a steady state, which is likely maintained by the reflex activity of the lower motor neuron (spasms). In addition, in the present paper, we show that most fibers from long-term paraplegics, despite the time elapsed from injury (14-20 years), present a fairly well-preserved contractile material (Figure 5), which provides the structural features needed to develop mechanical tension. To our knowledge, this is the first time that muscle from spastic patients that have been paralyzed for such an extended time have been studied under EM at high magnification.

Published literature supports the notion that, although spasticity is multifactorial and neural in origin, significant structural alterations in muscle of paraplegic patients may also occur. This is confirmed in the present study. In fact, substitution of some collective muscle fiber area with connective tissue occurs in our samples (about 30\%, see Figures $3 \mathrm{~d}$ and e). Presence of this abnormal amount of connective tissue may contribute to the muscle weakness and stiffness of the extremities in paraplegics. Anyhow, midterm and long-term paralyzed leg muscles show an almost identical percentage of interstitial tissue, supporting the idea that, after the first couple of years, the general condition of muscle tissue remains stationary.

Furthermore, our histological, immunohistochemical and ultrastructural analyses indicated that not all the fibers in these patients maintain trophism and a striated interior. In fact, some muscle fibers (up to $50 \%$ in some muscle biopsies) closely resemble those found in Cauda Equina Syndrome, ${ }^{7,8}$ as if they have been completely inactive for many years; they are very small and closely resemble those found in lower motor neurons lesion injury. The presence of these severely atrophic fibers strongly suggests that at least some fibers have lost their peripheral nerve. The presence of these 'denervated' fibers actually represents an internal control, which allows to clearly distinguish those fibers that maintain connection to the axon (larger in diameter and clearly striated). The lack of correlation between the duration of paralysis and the percentage of severely atrophic muscle fibers keeps open the issue of whether their decrease in number in long-term paraplegic muscle is the consequence of: (i) the small size of our cohort, (ii) long-term reinnervation or, more likely, (iii) apoptosis/necrosis of the long-term lower motoneuron-denervated muscle fibers.

The above conclusions remain valid even if the data are analyzed excluding from the mid-term group the MT1 patients (the female participant) whose results appear to be different from those of the other male subjects.

In Table 4 , the force of the long-term group appears decreased when the comparison is made with the mid-term group excluding MT1, but the difference remains statistically non-significant. Furthermore, the results of the CT scans and the muscle morphometry at best differ among the mid- and long-term groups by 5-20\%, but the changes are statistically significant only in some CT scan comparisons.

The third, more important result of the present study is the explanation of the paraplegia paradox. Contractile material seems to be quite well preserved, in spite of the poor functional outcome of paraplegic muscles, which are much weaker and fatigable than their normal counterparts. ${ }^{1-3}$ Our ultrastructural analyses presented in Figure 6, which identified fine alterations of the internal organization of EC coupling and metabolic machineries, could provide additional explanation for the impaired function of the musculature in spastic patients (beside that related to muscle fiber size, enlarged extracellular matrix and the presence of some peripheral denervation). The misalignment of the contractile apparatus, accompanied by the formation of abnormal areas filled with glycogen granules, mitochondria and vesicles, as well as the structural alteration of the metabolic (mitochondria) and activating (sarcotubular) apparatuses, could definitely account for the poor function of spastic muscles, which are weak (low specific force) and fatigable (low endurance) in spite of their not-so-small mass.

Despite the enormous differences in the time of palsy, the parameters analyzed in the present study showed small differences between mid-term and long-term paralyzed muscles, with the possible exception of quadriceps muscle force, in particular, when the MT1 subject is excluded from the mid-term group, (but the difference remains statistically not significant in Table 4). In complete SCI subjects, the absence of pain sensation does not limit the deliverable electrical currents, as it happens in able-bodied subjects and incomplete SCI. So, in order to limit current density and avoid skin damage, we had to use large electrodes and constant voltage stimulation. This was the only clinically viable way to measure near-maximal force of paralyzed muscles while avoiding risks of skin burns, ${ }^{20}$ in spite of the fact that agonist and antagonist muscles were stimulated at the same time and therefore the transducer did not measure the actual force of the trained quadriceps muscle.

Our results may be of importance for the treatment of paraplegic patients. In fact, the long-lasting maintenance of muscle functional and structural properties suggest that treatments may be started at any time after the injury in these types of patients, possibly with the same, or similar, efficacy. In conclusion, our findings scientifically support the notion that even during the late stages of upper motoneuron paraplegia, there are no upper-time limits (at least, up to 20 years after SCI) to successfully start a training program by FES.

\section{Acknowledgements}

We thank Katia Rossini, Valerio Gobbo, Susy Caccavale, Nicoletta Adami and Donatella Biral for morphometry of light microscopy analyses. This work was supported by the Austrian Ministry of Transport, Innovation and Technology 'Impulsprogramm' Grant No.: 805.353 and Otto Bock Healthcare Products GmbH Vienna, Austria; research funds from the Ludwig Boltzmann Institute for Electrostimulation 
and Physical Rehabilitation at the Institute of Physical Medicine and Rehabilitation (Wilhelminenspital, Vienna, Austria); the Italian C.N.R. funds and the Italian MIUR funds (ex60\%) and PRIN 2004-2006 Program (Contract n. 2004061452-002) to UC; research funds from the University G d'Annunzio of Chieti to FP Sponsorship: Austrian Ministry of Transport, Innovation and Technology 'Impulsprogramm' Grant No.: 805.353 and Otto Bock Healthcare Products GmbH Vienna, Austria.

\section{References}

1 Graupe D. An over view of the state of the art of non-invasive FES for independent deambulation by thoracic level paraplegics. Neurol Res 2002; 24: 431-442.

2 Kern H, McKay WB, Dimitrijevic MM, Dimitrijevic MR. Motor control in the human spinal cord and the repair of cord function. Curr Pharm Des 2005; 11: 1429-1439. Review.

3 Lieber RL, Steinman S, Barash IA, Chambers H. Structural and functional changes in spastic skeletal muscle. Muscle Nerve 2004; 29: 615-627.

4 Carlson MC, Borisov AB, Dedkov EI, Dow D, Kostrominov TY. The biology and restorative capacity of long-term denervated skeletal muscle. Basic Appl Myol 2002; 12: 47-254.

5 Carraro U. Modulation of trophism and fiber type expression of denervated muscle by different patterns of electrical stimulation. Basic Appl Myol 2002; 12: 263-273.

6 Midrio M. The denervated muscle: facts and hypotheses. A historical review. Eur J Appl Physiol 2006; 98: 1-21.

7 Kern H, Boncompagni S, Rossini K, Mayr W, Fanò G, Zanin ME et al.. Long-term denervation in humans causes degeneration of both contractile and excitation-contraction coupling apparatus that can be reversed by functional electrical stimulation (FES). A role for myofiber regeneration? J Neuropath Exp Neurol 2004; 63: 919-931.

8 Carraro U, Rossini K, Mayr W, Kern H. Muscle fiber regeneration in human permanent lower motoneuron denervation: relevance to safety and effectiveness of FES-training, which induces muscle recovery in SCI subjects. Artif Organs 2005; 29: 187-191.

9 Modlin M, Forstner C, Hofer C, Mayr W, Richter W, Carraro U et al. Electrical stimulation of denervated muscles: first results of a clinical study. Artificial Organs 2005; 29: 203-206.

10 Lotta S, Scelsi R, Alfonsi E, Saitta A, Nicolotti D, Epifani P et al. Morphometric and neurophysiological analysis of skeletal muscle in paraplegic patients with traumatic cord lesion. Paraplegia 1991; 29: 247-252.

11 Scelsi R. Skeletal muscle pathology after spinal cord injury. Our 20-year experience and results on skeletal muscle changes in paraplegics, related to functional rehabilitation. Basic Appl Myol 2001; 11: 75-86.

12 Gorgey SA, Dudley GA. Skeletal muscle atrophy and increased intramuscular fat after incomplete spinal cord injury. Spinal Cord 2007; 45: 304-309; advance online publication, August 29, 2006; doi:10.1038/sj.sc.3101968.

13 Taylor PN, Ewins DJ, Fox B, Grundy D, Swain ID. Limb blood flow, cardiac output and quadriceps muscle bulk following spinal cord injury and the effect of training for the Odstock functional electrical stimulation standing system. Paraplegia 1993; 31: 303-310.

14 Giangregorio LM, Webber CE, Phillips SM, Hicks AL, Craven BC, Bugaresti JM et al. Can body weight supported treadmill training increase bone mass and reverse muscle atrophy in individuals with chronic incomplete spinal cord injury? Appl Physiol Nutr Metab 2006; 31: 283-291.

15 Andersen JL, Mohr T, Biering-Sørensen F, Galbo H, Kjaer M. Myosin heavy chain isoform transformation in single fibers from $\mathrm{m}$. vastus lateralis in spinal cord injured individuals: effects of long-term functional electrical stimulation (FES). Pflugers Arch 1996; 431: 513-518.

16 Castro MJ, Apple Jr DF, Staron RS, Campos GE, Dudley GA. Influence of complete spinal cord injury on skeletal muscle within 6 mo of injury. J Appl Physiol 1999; 86: 350-358.

17 Crameri RM, Weston AR, Rutkowski S, Middleton JW, Davis GM, Sutton JR. Effects of electrical stimulation leg training during the acute phase of spinal cord injury: a pilot study. Eur J Appl Physiol 2000; 83: 409-415.

18 Adams MM, Ditor DS, Tarnopolsky MA, Phillips SM, McCartney $\mathrm{N}$, Hicks AL. The effect of body weight-supported treadmill training on muscle morphology in an individual with chronic, motor-complete spinal cord injury: a case study. J Spinal Cord Med 2006; 29: 167-171.

19 Mohr T, Andersen JL, Biering-Sorensen F, Galbo H, Bangsbo J, Wagner A et al. Long-term adaptation to electrically induced cycle training in severe spinal cord injured individuals. Spinal Cord 1997; 35: 1-16.

20 Kern H, Hofer C, Mödlin M, Forstner C, Raschka-Högler D, Mayr W et al. Denervated muscles in humans: limitations and problems of currently used functional electrical stimulation training protocols. Artificial Organs 2002; 26: 216-218.

21 Rossini K, Zanin ME, Podhorska-Okolow M, Carraro U. Stage and quantify Regenerative Myogenesis in human long-term permanent denervated muscle. Basic Appl Myol 2002; 12: 277-286.

22 Rossini K, Biral D, Carraro U, Mayr W, Kern H. N-CAM and isomyosins of long-term denervated human muscle. Basic Appl Myol 2006; 16: 108-110.

23 Sanger JW, Sanger JM, Franzini-Armstrong C. Assembly of the skeletal muscle cell. In: Engel AG and Franzini-Armstrong C (eds). Myology, 3rd Edn. McGraw-Hill Med Publish Div: New York, 2004 Vol. 1, pp 45-65.

24 Franzini-Armstrong C. The membrane systems of muscle cells, In: Engel AG and Franzini-Armstrong C (eds). Myology, 3rd edn. McGraw-Hill Med Publish Div: New York, 2004 Vol. 2, pp 232-256.

25 Boncompagni S, d'Amelio L, Fulle S, Fanò G, Protasi F. Progressive disorganization of the excitation-contraction coupling apparatus in ageing human skeletal muscle as revealed by electron microscopy: a possible role in the decline of muscle performance. J Gerontol Biol Sci 2006; 61: 995-1008.

26 Ogata T, Yamasaki Y. Scanning electron-microscopic studies on the three-dimensional structure of mitochondria in the mammalian red, white and intermediate muscle fibers. Cell Tissue Res 1985; 241: 251-256.

27 Bolanos P, Guillen A, Rojas H, Boncompagni S, Caputo C. The use of CalciumOrange- $5 \mathrm{~N}$ as a specific marker of mitochondrial $\mathrm{Ca}(2+)$ in mouse skeletal muscle fibres. Pflugers Archiv. Eur J Physio 2007 (e-pub ahead of print: 18 August) PMID: 17705046. 